\title{
TRANSPARENCY OF DEFENCE POLICY IN PROGRESS
}

\section{Tilcho IVANOV}

Following the end of the Cold War at the end of the last century, Bulgaria has 1990s, policy was essentially driven by the aim to overcome the centralist legacies
experienced unprecedented changes of its defence policy. At the beginning of the and to lay the new constitutional basis for democratic governance and a viable defence administration. ${ }^{1}$ Later the driving force was the challenge of joining NATO. Recent management changes have been increasingly shaped by imminent accession. Despite this positive evolution, with regard to the transparency of policy there remain issues to be explored and harmonised.

This essay looks at Bulgaria's practice in openness and transparency of defence policy in the context of driving democratic approaches to solving the country's problems. A key aim is to clarify the status of defence policy openness and transparency and to suggest how officials could improve the effectiveness and quality of policy execution. The material covers

- Defence policy and public communication;

- Delivery of justice and defence strategy planning in transition;

- Changes in central (core) ministerial structures;

- Defence planning, programming, and budgeting transparency;

- Transparency of procurement policy;

- Transparency and information security policy;

- New operational defence management modernisation in practice.

At the end there are some conclusions and proposals for the modalities and paths ahead. 


\section{Defence policy and public communication}

Transparency is a main precondition of civil control and accountability of public governance in defence. As the main responsibility of the government in the liberal democratic state is to protect the public interest, it must therefore be ready to inform the general public about its decisions. Related to defence policy there must be relevant openness, clarity, and credibility. The important key documents and other information prepared or commissioned by the government, including Ministry of Defence (MoD) and defence agencies, should be made available to the public. ${ }^{2}$

One of the main objectives of administrative reform in Bulgaria, as a transitional country, is the growing accountability of governance. The explanation lies in the development process of the state, a century-long transformation from the Liberal State, through Social State to Market State.

The classic theory on the liberal-democratic state conceives it as a "complex structure of checks and balances, addressed mainly at preventing the abuse of power and at protecting the sphere of freedom and personal development that correspond to each individual and to the society at large." ${ }^{3}$ We will not discuss the reasons, but from the first third to the middle of the last century the Social State changed the Liberal European State. (In Eastern Europe the new state became the Socialist State.) As a consequence of this development the government became the dominant manager of society. The state became the "Bureaucratic State" in the West and even the "Authoritarian or Totalitarian State" in the East. The favoured principles and criteria for evaluation of central administration were-nominally, at least-efficiency, effectiveness and economy.

Reaction to that began in the 1980s. Since then the active, direct, and leading role of state bodies and apparatchiks has increasingly given way to a more passive, indirect, and facilitating role. ${ }^{4}$ The new Market State appears with less dominant central direction and fewer state-owned enterprises because of privatisation. All these changes affect governance. Attention to public participation, accountability and transparency accompanies a conception of the government as a partner-producer of public goods. "New governance" now views the citizen more as a client than as a subject or object of administration. That is what we call now "modern civil society."

In this setting successful capacity-building for 'good governance' rests on four key principles: transparency, accountability (and civil control), participation and predictability. ${ }^{5}$ These principles are interrelated, and transparency is a precondition for the rest. The level of accountability is the real criterion for gauging the build-up and development of modern civil society in any country, the measure of what is real and what is illusory in the process of transition to democracy. In this respect we can see that transparency is only one of the important criteria. It is a prerequisite for, but 
not a full guarantor of, accountability and democratic control. Governmental sensitivity to critics and readiness to answer to popular dissatisfaction with current policy are also important.

At the same time, in extreme cases, excess of openness and accessibility can have negative effect on transparency. This is the case when "People cannot see the wood for the trees." In real life, however, this case is very rare. Seemingly transparent but effectively closed government is not at all democratic. 'Good governance' requires provision of relevant information, according to the public interest. Limited transparency or openness betrays official reluctance to consider popular demands and accept democratic control.

According to Shamsul Haque there are three dimensions of accountability and transparency:

- The standards of accountability (accountability for what) and transparency;

- The agents of accountability (to whom) and transparency;

- The means of accountability (how it is ensured) and transparency. ${ }^{7}$

Each of these might instructively be analysed separately, but in this paper only a general overview is possible.

What the defence organisation and armed forces have to be accountable for-and transparent about - is the public service they render, evaluated in terms of both product and process. The transparency requirement extends to provision of information about both policy and resources. (Before defence reform gathered momentum in Bulgaria there were no standards or norms regarding these matters.)

Practice throughout the security sector should ideally respect both national and international expectations and requirements. There are few international prescriptions related to defence plans and budgets. Among the more important are:

- some UN conventions, including the Register of Conventional Arms (primarily concerned with transparency in trade);

- the OSCE's Vienna Document 1999 On the Negotiations on Confidence and Security Building Measures (outlining politically-binding obligations to share information concerning military forces, major weapon and equipment systems, defence planning and budgeting, including spending data);

- Stability Pact-sponsored exercises, like the Initiative on Transparency of Military Budgets in South-Eastern Europe.

The last-mentioned has yielded a pilot data Yearbook and work is in progress on a follow-up volume plus a Survey of budgeting processes in the region. 
As for national obligations in Bulgaria, it is appropriate to mention one regular and one occasional medium:

- the Yearly Report on the State of Defence (required by the Law on Defence), which has established a good start for routine reporting (but lacks data on budget execution);

- the Defence White Paper (or White Book), the inaugural edition of which appeared in 2002.

The last-mentioned took a long time to prepare but involved extensive public discussion on the national defence outlook. It is to be hoped that there will be further editions from time to time.

Regarding the second dimension - accountability to whom - in a democratic state this involves requirements related to civilian direction and democratic control. The armed forces must be answerable to ministers who are in turn answerable to elected representatives of the people (demos, in Greek). Further, these representatives should exercise legislative oversight of the entire defence organisation, and of policy and spending in particular. Policy-making, planning and budgeting should also be monitored by academics and NGOs, the print and broadcast media, and other institutions of civil society such as interest groups.

In Bulgaria as elsewhere the Minister of Defence occupies a pivotal position. He directs the military and the defence organisation, and in turn reports to the country's Security Council, Ministerial Council and National Assembly. He also has to present financial information, as required by legislation. His office broke new ground in 2001/2002 with the production of the aforementioned White Paper (White Book). No other authority has direct obligations to give specialised information to the Bulgarian public.

The demand for such information from NGOs, lobbies, the media, industries, other partners and clients is steadily increasing. This is in line with acceptance of a newliberal model of governance that is changing the composition of agents to whom the authorities should be accountable. Citizens see themselves as clients of the common services for which they pay their taxes. This is a new idea for Bulgarian bureaucrats, and it poses a big challenge, calling for greater openness all round.

The third dimension of transparency - concerning how accountability is ensured-is about means. Haque identifies two types of mechanism in the traditional practice of western liberal democracies:

- External-formal mechanisms, including legislative instruments (legislative committees and parliamentary questions), executive means (controls 
exercised by the authorities over public agencies), and judicial or quasijudicial processes (administrative courts and ombudsmen), plus externalinformal means, such as public hearings, opinion polls, interest group and media scrutiny;

- Internal-formal mechanisms, including hierarchies, official rules, codes of conduct, performance reviews; and internal-informal means, such as organisational culture, professional ethics, and peer pressure.

Like other transitional countries, Bulgaria has put formal machinery in place along these lines; and informal arrangements are evolving, helped by the greater availability of information (including recent development of the government's Web pages). Such communication facilitates public understanding and, by evoking a multiplicity of opinions, should contribute to better decision-making. ${ }^{8}$ Its legal underpinning includes a Law on Access to Public Information, affording access to the files of public organisations. ${ }^{9}$ Another important statute is the Law on Public Orders, giving rights to potential suppliers to receive equal information about contracts. ${ }^{10}$

From the point of instruments for enhancing transparency we need a good theoretical base to provide an appropriate perspective, common terms, and so on. Theories related to organisational communication offer a lot of approaches, methods, and techniques. Four packages of theories may be distinguished ${ }^{11}$ : (1) mechanistic, (2) psychological, (3) interpretive-symbolic and (4) system-interactive, each with its own premises, axioms and assumptions about different aspects of the communication process.

- The mechanistic approach looks on the message as composed of the divisible bits of information transmitted between the sender and receiver. Theory is focused on technical problems: the nature and capacity of the channels, noise factors, and suchlike.

- Psychological theories are based on the assumption that the predispositions of senders and receivers determine the nature and format of exchanged messages, and the type of attention and interpretation that they need to reach their targets.

- Interpretive-symbolic theory sees messages only as stimuli that lead to communication by creating understanding between sender and receiver. The understanding is a result of exchanging ideas based on shared perceptions, coming from a common sense of organisational existence that is a product of the existing organisational climate and culture.

- System-interactive theory analyses messages on the assumption that the working communication process is a significant indicator of how the organisation functions in practice. It focuses on the situational status of the 
organisation as a whole. It is directed to making predictions about message patterns, the quality of interaction, and the improvements that have to be implemented.

The last 'package' is closest to the approach in this article. Focusing our attention on recurring communication, we seek suggestions for improvement from the point of its openness and transparency.

\section{Delivery of justice and defence strategy planning in transition}

For Bulgaria as for other Central and Eastern European countries the practical question of openness and transparency is mostly a political one, reflecting rejection of a legacy. After the Cold War era Bulgaria espoused the ideas, principles, institutions and, at least nominally, the standards of accountability associated with the liberaldemocratic mode of governance. Most of the basic mechanisms and important instruments of control and accountability in a liberal-democratic state were accordingly prescribed by legislation. With the adoption of the 1991 Constitution, political forces embarked on extensive changes in the law.

This process extended to important initiatives for restructuring and reforming the public sector and its administration. The "market-led" state has begun to replace the inherited authoritarian state. Key statutes include new Laws for Defence and Military Forces (1995), the Audit Office (1995), State Financial Control (1995), for Public Procurement (1997), Administration generally (1999), and Civil Servants (1999). In the area of defence policy specifically the country adopted a new National Security Concept (1998) and Military Doctrine (1999), developed a blueprint for the development of the Armed Forces to 2004 (1999) and since 1999 has also followed the Membership Action Plan (MAP) process of preparation for accession to NATO. Further it began issuing an Annual Report on the Status of National Security in 1999 and, as noted earlier, one on Defence and the Armed Forces in 2000.

As well as these legislative and executive actions relate to civil direction and democratic control of defence domestically, governments have also paid attention to international obligations like the exchange of information according to the OSCE's Vienna Document $1999 .{ }^{12}$ In addition, on defence spending Bulgaria has taken the lead in furthering regional information-exchange (and publication) through its sponsorship — with the United Kingdom's help — of an Initiative for Defence Budget Transparency in South-East Europe. ${ }^{13}$ On the other hand, there have been 'deviations' from some international agreements and UN resolutions. A case in point is the UN Register of Conventional Arms, originally established on the assumption that it would cover not only exports and imports of conventional weapons but also "available background information" relating to equipment holdings and procurement from 
national production. According to independent studies, at the peak of the Kosovo conflict (1999) Bulgaria provided regular information but was at the same time supplying countries to which others refused to sell. ${ }^{14}$

There is a transparency aspect also to Bulgaria's participation in NATO's Partnership for Peace programme. Since 1995 the special Planning and Review Process (PARP) has required the production of information about participants' equipment, their forces' deployability and readiness, with particular reference to capabilities that countries offer to make available for multinational formations and contingency operations. The main instruments for transparency through PARP are: Ministerial Guidance, Partnership Goals, and the (biennial) Survey.

To sum up: it is clear that Bulgaria has accepted the main principles and procedures relevant to the democratic control of defence, and policy and practice regarding transparency and accountability rest on a sound initial base. However, there remain significant variations between what happens here and what is commonplace in mature democracies. On the domestic side, for instance, as a general rule the proceedings of the legislature's Committee for External Policy, Defence and Security are not open to the public (though in certain circumstances the Committee can decide that they should be). This position should be corrected - the sooner the better-by amending the terms of the Regulation for the Activity of the National Assembly. ${ }^{15}$ There are other areas where there remains room for improvement: not so much through further refinement of laws and regulations as through greater diligence, on the part of both the executive and the legislature, in implementing the rules; and through more effort to establish a robust culture of transparency.

\section{Changes in central (core) ministerial structures}

Since the early 1990s there has been far-reaching structural change in the defence organisation, including the Ministry of Defence $(\mathrm{MoD})$ where functions have been rationalised and personnel numbers reduced (from approximately 800 to around 300). Reform has been explained in official publications and on the MoD's website. It has respected the Law on Administration's call for unified ministerial structures, based on common organisational rules; and it has been influenced by the impulse to follow NATO member states' practice as communicated through the MAP and PARP processes.

As a result of that, the current core structure of the Ministry includes six different blocs: Political Cabinet, General Administration, Specialized Administration, Executive Agencies, Academies, and Information and Security Services. Specialized administrative bodies (directorates) deal with key areas of business: Defence Policy and Planning; Armaments Policy; Personnel Policy and Social Adaptation; Euro- 
Atlantic Integration; International Co-operation; Procurement Management; Budget Planning and Management; Financial Control; Military Infrastructure; and Legal Activities.

Notwithstanding the record of generally positive changes across the defence organisation as a whole, there remain a lot of unsolved questions. Areas in which there is unfinished business include the following:

- Development of transparent internal organisational regulations for the separate directorates to guarantee 'open' government;

- Development of an integrated administrative structure (MoD and General Staff) to reduce an existing redundancy of functions and personnel;

- Development of a law and normative base for the executive agencies to allow some autonomy of activity without sacrifice of accountability;

- Improvement of the organisational ability of the MoD in the area of innovation, investments, and R\&D activities.

The point is that shortcomings in the machinery of government are an obstacle to the consolidation of transparent and accountable governance.

\section{Defence planning, programming, and budgeting transparency.}

Turning from structure to process, what about practice in the key area of defence planning, programming, and budgeting; and what problems arise in achieving 'open' government here? On the whole the Bulgarian story is one of commendable progress in provision for accountability and transparency in this field. By and large the country has overcome the obstacles that in many other transition states have resulted in politicised administration, increasing corruption and negative attitudes concerning defence and security-sector reform. Such states often find it hard to shed their authoritarian inheritance. Citizens lack elementary mechanisms for control of power ministers, prosecutor's office and administration. They may protest at this; but they may also acquiesce, opting for patronising paternalism rather than developing an active civil society. That has been the position in several South East European countries, where a tradition of closed governance prevails. In some cases the cause is lack of jurisdiction; in others it is legislative nihilism or infirmity. Either way, in such countries "the rule should be to increase transparency and openness, without hiding behind sophistic arguments and pseudo-calculations."16

Bulgaria has done that. Thanks to the efforts of many administrators and specialists, since 1999 the country has evolved a "Planning, Programming, and Budgeting System" of the sort that most western countries use. This provides a coherent procedural framework within which decision-makers can identify what forces and 
capabilities are needed (planning); determine how and when they will be acquired, and what will be an affordable cost (programming); and allocate appropriate funds (budgeting). At the same time the system makes it possible to demonstrate to elected representatives and citizens why taxpayers' money is necessary for defence, and how precisely it will be spent (appropriately and wisely in an ideal world). ${ }^{17}$

Bulgaria does this to some extent. The official portfolio of publications is not, however, as comprehensive as it could be. This is apparent if one looks at the material leading western states produce, which includes most or all of the following ${ }^{18}$ :

- Annual Report of the Minister of Defence (accompanied in the United States - but nowhere else - by a detailed Posture Statement from the Joint Chiefs of Staff plus several volumes of complementary information);

- Defence White Book or White Paper, typically an occasional statement but an annual publication in the United Kingdom; or periodic planning prospectus, like France's regular Lois de programmation;

- Annual budget publication supporting the government's formal request for funds for all its spending departments (including defence), with essential information on resource allocation;

- Publications of the relevant parliamentary committee (or committees) overseeing the Defence Ministry and responsible for reporting the economy, efficiency and effectiveness with which the Ministry is discharging its responsibilities;

- Publications of the states 'Supreme Audit Institution' (local designations differ), incorporating critical commentary on the executive branch's use of taxpayers' money (for all public administration and defence);

- Publications of the MoD or its policy-making, planning and procurement bodies, containing information elucidating policy and plans, procurement procedures and contracts.

The British also produce two other valuable texts, namely (i) a Major Projects Statement, which gives progress reports on all 'big ticket' equipment acquisitions, with important cost information, and (ii) a compendium of Defence Statistics, which contains data on expenditure and manpower (including statistics on the industrial and regional distribution of spending and on payments to major contractors).

Such documentation gives the citizens of liberal democratic states all important information about the main decisions taken by the defence organisation. It makes planning, programming, budgeting and budget execution adequately transparent, serving democratic accountability. For such states, where civil society institutions have been active for decades, domestic transparency is therefore not a current issue. ${ }^{19}$ 
It is mostly respected through the good practices and proper policy of governments. Moreover, this accords with contemporary notions of applying performance management criteria in the evaluation of public administration as "organizations in the public sector are shifting their whole steering concept from traditional input control to an explicit output or outcome focus." 20 Where countries hold administrators responsible for achieving performance targets, transparency is an essential instrument for the accountability of public servants.

Against this background the shortfalls in Bulgaria's 'official portfolio' are selfevident. The conspicuous omissions are publication of (a) detailed information about the government's formal request for funds for all its spending departments (including defence) with essential information on resource allocation, and (b) the findings of the specialist committee that oversees the Defence Ministry. Lack of an equivalent to the British Major Projects Statement and of a regular compilation of defence statistics is noteworthy also.

Obviously there is no universal rule or model for control, accountability and transparency of defence policy-making and planning, programming and budgeting in democratic countries. Bulgarian practice compares favourably with that in other South-East European countries. However, there is still room for further improvement.

\section{Transparency of procurement policy}

Defence acquisition is the integrated process of research and development, and purchase, of the goods and services that the defence organisation and the armed forces need to support policy for the external security of the country. Openness and transparency are crucial to sound decision-making in this area, in accordance with Karl Deutsch's celebrated dictum that "the essence of governmental organizations is decision making, and the essence of decision making is communication." ${ }^{21}$ It is appropriate therefore to pay special attention to how the Ministry of Defence and its directorates operate, and manage information, in relation to military $R \& D$ and procurement.

Concern about openness and transparency in the acquisition process arises especially in countries like Bulgaria because its execution is becoming more and more difficult in the period of transition from authoritarian to democratic governance. Changes are needed also because of the increasing participation of private and semi-public organisations like universities and research institutes in $R \& D$, and of private companies in defence supply. These organisations are concerned not only about openness but also about bureaucracy. The MoD is starting to allot more funds to arms and equipment modernisation. The new private suppliers need essential, relevant and timely information about potential supply contracts. The citizens and civil society 
institutions - like NGOs, interest groups and the media - also have the right to know how effectively and efficiently defence money is being disbursed.

Satisfactory communication about acquisition is perhaps the most problematic issue for the image of any defence organisation. The Bulgarian administration is faced with complex issues that were unknown only a few years ago. Positive developments include enactment of a Law for Public Orders and a Regulation for Assigning Public Orders. ${ }^{22}$ The Minister of Defence has also promulgated an Instruction for Planning, Organization of Assignment and Control of Supply and Construction Services. Further, an open Register of Public Orders has been instituted since approval of the new Law. On the face of it, taken together these instruments constitute a sound basis for the management of future military procurement. However, in practice there is insufficient transparency, and widespread suspicion of bad deals about which only limited information has come to light. The problem lies in Article 6, Paragraph 1 of the key Law which exempts any public orders related to the defence and security of the country that are declared state secrets.

Fortunately, increasing international engagement - principally within the frame of NATO - is raising expectations for both external transparency and internal openness on acquisition matters. Attention is therefore being paid to important target audiences. $^{23}$ The challenge is to identify the segments of the polity and society rightfully concerned in the issues and to ensure that they get appropriate information. Obviously relevant groups to be addressed include higher authorities in the defence organisation itself, parliamentarians and other elected office-holders, auditing officials, NGOs engaged in analysing defence affairs plus academic and research institutes directly involved in $\mathrm{R} \& \mathrm{D}$, potential international and national business suppliers, members of the news media, and citizens.

Every member of the Defence Acquisition Directorate contributes to the identity of the organisation and the image projected to the public. The Directorate needs to invest in effective communication management, and work to an appropriate communication plan. Officials have to stand ready to deliver high-quality presentations. The Directorate has to issue and disseminate informative publications tailored to the needs of the identified target audiences. Attention to feedback-an important element in any communication process - is clearly necessary also.

\section{Transparency and 'information security' policy}

Despite the arguments in favour of both domestic and international (or regional) transparency regarding defence affairs, it is clear that sources of information about military matters should ordinarily be under the strict control of the executive branch in each individual country. For one thing, there are data to which a state may 
legitimately wish to deny access by ordinary citizens, but which it is obliged - or thinks it worthwhile - to share with other governments. This is a real problem, explicable by differences between internal law and internationally accepted commitments. Controlling disclosure should not, however, entail ruling-out release of non-sensitive material that the domestic public has the right to know.

At the same time, from the "security" point of view there are many cases where widespread dissemination of confidential information on particular aspects of defence policy could be judged to be against the national interest. Domestic legislation on this varies according to historical experience and the particular understanding of national interests, as do the terms on which states have subscribed to different international and bilateral agreements.

However there should be a disposition towards openness between neighbouring states for the sake of confidence- and trust-building. Good neighbours are not obliged to exchange information, but they do not withhold information that relates to the legitimate concerns of others. Secrecy is the enemy of trust and openness builds confidence.

Still, one cannot say unreservedly that the more transparency and openness the better. They have to be taken in correct dosage, according to the "internal quality of democracy" and "external building of confidence and security." Neither is unconditional or absolute. Thus in times of threat, crisis or conflict-as when acts of terrorism are feared - they have to be considered in relation to potential risks. In such cases limitation of some citizens' rights is natural and acceptable. A value judgment is necessary on how much transparency and openness to sacrifice in order to safeguard the security of citizens. The general problem is simply that in some circumstances it is quite difficult to protect the national security interest and at the same time allow access to sensitive information. The statutes about classified information have to be directed to resolving this tension.

Even when the 'national security interest' is not touched directly, allowing free access to some information can be troublesome. This may be the case when public bodies negotiate contracts or agreements within the state sector or with outside organisations. Sharing sensitive information with all (competing) parties may make it harder to strike a successful bargain. This situation induces public managers to adopt a conservative operating style. To assure accountability of their own activity they tend to cling to the letter rather than to the spirit of the law. Their behaviour becomes more 'bureaucratic' than is either necessary or acceptable.

In the beginning of the 1990s, Bulgaria inherited a strong system of classified information. According to old authoritarian standards almost everything related to defence was secret. Formally, the legacy survived until 2002, when the National 
Assembly accepted a new Law on Classified Information. ${ }^{24}$ That was the right response to a decade of steadily decreasing official secrecy. Matters came to a head early in 2002 over the inability of the Council of Ministers to safeguard sensitive information about a contract, signed with the "Crown Agents" - a British organisation tasked to tackle corruption in the National Customs Agency. Distribution of this information helped the opposition start a big parliamentary and public debate about government policy. The case raised familiar questions about classifying material. Classification is necessary for keeping national military secrets, but it can be used as 'cover' for sensitive information that should be open to scrutiny. It is important to have a satisfactory system for clearance of persons working with classified information, even though this is time-consuming and costly.

Other questions arise in view of Bulgaria's imminent accession to NATO. They include whether the special Service of the MoD that controls access to Bulgaria's military secrets should change its ways. There is the obligation to protect material provided by NATO and other shared sensitive information, something the 2002 Law was designed to cover. However, in the name of 'information security' this statute errs on the side of caution. Regrettably it sanctions continued classification of much that was inaccessible under the former, supposedly too secretive, arrangements. This reveals a continuing tendency to exaggerate security threats and/or reflects officials' judgement that it is safer to be overzealous in labelling documents as secret (and tightly controlling them) than to take care over the distribution of sensitive information.

\section{New operational defence management modernisation in practice}

Yet there must be communication if defence administrators are to get regular feedback on the effectiveness of policy execution in order to make improvements. It is unsatisfactory if observers are frequently frustrated in their attempts to determine how defence administrators formulated their objectives and employed public resources to fulfil them. All this produces is media complaints of excess secrecy surrounding actions and poor use of resources. (Reported successes are rare.) Typically, though, comprehensive information on the basis of decisions and actions, and on the effectiveness of their execution, is hard to obtain.

Development of an assessment culture and adoption of good management practices needs time and systematic endeavour. The important precondition is acceptance of programme management in organising the national defence effort. This facilitates development of relevant analysis of policy and proper appraisal of executed programmes. It presupposes, of course, the education and training of defence administrators for policy analysis and programme evaluation. In Bulgaria this is appropriate, desirable, and possible. 
The bases of defence policy assessment are (a) performance measurement, and (b) programme monitoring and evaluation. These instruments and techniques have common purposes: to make dispositions open and transparent-through improving programme management - and increase accountability. They are focused on better decision-making, as they feed back information on the outcomes and outputs of defence policies and key programmes in order to improve the design and implementation of future programmes.

Performance measurement involves assessing progress against stated programme goals and objectives, assuming that the strategic objectives are known. It comprises two main activities:

- Analysing the "production process," which consists of processes and activities used to turn resource inputs into outputs, viz. the defence services (or capabilities) directly produced by the programme;

- Appraising the outcomes, which extend to the broader economic or social changes resulting from a policy or programme, and comparing these with the programme objectives.

Performance measurement may indicate in general terms the result of a policy measure or programme, but cannot reveal how and why outcomes occurred or what changes may need to be made to activities or objectives. For this purpose, in-depth assessment is needed.

Programme evaluation extends beyond the tracking and monitoring of performance measures into an examination of the ways in which outcomes are affected by the programme concerned. Whilst performance measurement focuses on efficiency and effectiveness, evaluation covers in addition issues such as the utility, relevance and sustainability of the programmes concerned. From this point of view the defence ministry, the executive branch of government and the legislature should ideally organise systems dedicated to monitoring policy (and budget) execution. At the parliamentary level there is a strong argument for creation of a special body for this purpose. In the Bulgarian case it might be a sub-committee of the National Assembly's Committee for External Policy, Defence and Security or, better perhaps, a separate Committee for Defence.

In general, the functions of the policy (and budget) execution assessment, programme monitoring and evaluation have to include:

- Identification of the institution(s) responsible for specifying policy objectives and programming resources;

- Control of the standard monitoring reports, prepared by the internal defence or other executive bodies; 
- Provision of external guidelines for budget execution assessment and programme evaluation, and consideration of how to improve assessment and evaluation.

To guarantee feedback for the improvement of policy and budget execution the management body has to ask such questions as: 'What are the results of evaluation of the effectiveness of policy execution and the spending of defence budget?' and 'What are the consequences of the assessment and evaluation at the executive and political level?'.

\section{Conclusion}

Bulgaria has accepted the main important principles and procedures relevant to the democratic control of defence policy and provision. Practice does not yet, however, accord with that in older democratic countries. Insufficiency of transparency is partially attributable to the persistence of the Cold War legacy and deep-rooted traditions.

Put another way, it is a reflection of how 'transition' has proceeded in the country. What transpires in any state is influenced by the type of democracy favoured (parliamentary or presidential) and by the balance of political power. Differences depend on how power is shared between the legislative and executive branches of government, as well as on the judiciary's role. In the cases where balance - or the 'separation of powers'-is flawed, the outcome is often limited democratic control, inadequate accountability and insufficient transparency. Among other things, this creates conditions in which large-scale corruption and hard-line bureaucracy thrive. The result is limited and unstable democracy. The crucial variables are the degree of transformation that has taken place, from the habits and practices of the authoritarian state to a situation in which the institutions of civil society have a voice and the extent to which political power has shifted from the executive authorities to civil society. Transparency is the guarantor of accountability, and thus fundamental to democratic control and oversight of defence. There can be openness, however, only where there is a clear and unequivocal division of roles and responsibilities between the government-in-office (the administration), the people's elected representatives (parliament) and society-at-large. That is why this 'balance' is a classic precondition for democracy.

The achievement of greater transparency depends first and foremost on the commitment of politicians and civil administrators to openness in the conduct of defence affairs. It will increase if they are able and willing to acknowledge accountability as an executive obligation, and to accept that their actions should be subject to democratic control. Transparency also requires proper legal underpinning. 
The sooner an improved statutory base for transparency of defence policy and provision is in place the surer the prospect of progress. But passing laws and regulations is obviously not sufficient in itself. What matters is the quality of the legislation and, most important, its effective implementation. Neither political nor legal effort nor administrative diligence is, however, as important as the determination of the society to make openness part of the nation's democratic political culture.

Every initiative for the modernisation of Bulgaria's defences is adding to popular understanding of the importance and complexity of accountability and transparency, and of the need to reinforce their development. National efforts for democratisation have also been supported by regional and international initiatives. Noteworthy accomplishments of recent years are the parliamentary approval and publication of the medium-term strategic plans for development of the armed forces, and the introduction of the programme budget plus information on forward procurement programmes (with concrete projections for equipment acquisition). Harmonisation of national law regulations with the acquis communautaire of the European Union and of MoD practice with NATO's expectations and requirements regarding public information - a precondition for joining those organisations - is clearly going to help consolidate democratic transformation.

The positive step ahead will be the organisation of a permanent audit of nationally accepted practices, and initiation of a process aimed at systematic and continuous improvement. Among the questions such an audit should address are the following:

- Are strategic defence goals relevant to the security environment?

- Are there clear statements of the objectives of defence policy?

- Is there a coherent plan for necessary change?

- Is effort made to assess the performance of the defence organisation?

- What kind of system of measurement is used?

- How frequently, and to whom, are the results reported?

- Where are the results published?

- How often are public attitudes gauged?

- How are opinion surveys conducted?

- Do civil society bodies, and citizens, actively demand defence transparency?

Satisfactory answers to such questions will signal not only progress towards a sound national defence policy but also the end of the post-communist transition and acceptance of the basic standards of democratic countries in policy-making, programming and budgeting. 


\section{Notes:}

$1 \quad$ Constitution of the Republic of Bulgaria (Sofia: National Assembly, 1991).

2 Nils Bruzelius, Bent Flyvbjerg and Werner Rothengatter, "Big decisions, big risks: improving accountability in mega projects", International Review of Administrative Sciences 64, no. 3 (September 1998): 423-440.

3 Antonio Bar Cendón, “Accountability and Public Administration: Concepts, Dimensions, Developments," in Openness and Transparency in Governance: Challenges and Opportunities, Second NISPcee Civil Service Forum (Maastricht, The Netherlands: 2829 October 1999), <http://unpan1.un.org/intradoc/groups/public/documents/nispacee/ unpan006506.pdf> (11 March 2003).

B. Guy Peters and Jon Pierre, "Governance without Government? Rethinking Public Administration," Journal of Public Administration Research and Theory 8, 2 (April 1998): 223-243.

$5 \quad$ Merilee S Grindle and Mary E. Hildebrand, "Building Sustainable Capacity in the Public Sector: What can be done?" Public Administration and Development 15 (1995): 441463.

B.J.M. Baron von Voorst van Voorst, “Opening Speech,” in Openness and Transparency in Governance: Challenges and Opportunities, The Second NISPAcee Civil Service Forum (Maastricht, The Netherlands, 28-29 October 1999), <http://unpan1.un.org/ intradoc/groups/public/documents/nispacee/unpan006504.pdf> (11 March 2003).

M. Shamsul Haque, "Significance of Accountability under the New Approach to Public Governance," International Review of Administrative Sciences 66, no. 4 (December 2000): 599-618.

Doris A. Graber, Public Sector Communication: How Organizations Manage Information, 2nd edition (Washington D.C.: Congressional Quarterly Press, 1992).

Law on the Access to Public Information, State Gazette 55 (July 2000).

Michael M. Harmon and Richard T. Mayer, Organization Theory for Public Administration (Boston, MA: Little, Brown and Co., 1986), p. 329.

11 Fredric M. Jablin, Linda L. Putnam, Karlene Roberts, and Lyman Porter, eds., Handbook of Organizational Communication: An Interdisciplinary Perspective (Thousand Oaks, CA: Sage Publications, 1987).

Vienna Document 1999 of the Negotiations on Confidence- and Security-Building Measures, FSC.JOUR/275 Istanbul, 16 November 1999, <http://www.osce.org/ docs/english/1990-1999/csbms2/vienn99e.htm> (23 March 2003).

Yearbook on South-East European Defence Spending, Stability Pact for South Eastern Europe (Sofia, Bulgaria: Budget Transparency Initiative, 2002), <http://www.stabilitypact.org/yearbook/index.htm> (27 October 2002).

Malcolm Chalmers and Owen Greene, "In Need of Attention: The UN Register in its Seventh Year," Bradford Arms Register Studies, Working Paper 7 (February 2000) <http://www.brad.ac.uk/acad/peace/pubs/bars7.pdf> (5 April 2002).

Regulations for the Activity of National Assembly, State Gazette 69 (2001), 86 (2001).

Yebezkel Dror, Transparency and Openness of Quality Democracy, in Openness and Transparency in Governance: Challenges and Opportunities, The Second NISPAcee Civil Service Forum (Maastricht, The Netherlands, October 1999), 
〈http://unpan1.un.org/intradoc/groups/public/documents/nispacee/unpan006507.pdf〉 (12 March 2003).

17 Neil V. Davies, "Planning, Programming and Budgeting - an Overview," EAPS (ECONC) D (2001) 3, no. 3 (December 2001).

18 David Greenwood, Resource Allocation and Resources Management in Defence: Western Model (Sofia: Stopanstvo Publishing House, 1997).

19 Ernest Gellner, Conditions of Liberty: Civil Society and Its Rivals (London: Hamish Hamilton, 1994).

20 Christoph Reichard, "The Impact of Performance Management on Transparency and Accountability in the Public Sector," in Ethics and Accountability in a Context of Governance and New Public Management, ed. A. Hondeghem and EGPA (Amsterdam: EGPA Yearbook, 1998), pp. 123-137.

Karl Deutsch, The Nerves of Government: Models of Political Communication and Control (New York: Free Press, 1966).

Regulation for Assigning Public Orders below the Limits of Article 7, Paragraph 1 of the Law for Public Orders, approved by Decree \#59 of the Ministerial Council from 2000.

Kenneth M. Wheeler, ed., Effective Communication: A Local Government Guide, (Washington D.C.: ICMA, 1994).

Law for Protection of the Classified Information, State Gazette 45 (Sofia, 30 April 2002).

TILCHO IVANOV is Head of the Department of National and Regional Security at the University of National and World Economics in Sofia. He graduated from the Technical University of Sofia in 1968 and received a Ph.D. degree in Economics and Management in 1978. He is Professor on Defence and Security Economics and Management. For a short period in 1999, Prof. Ivanov was Director of the Institute for Advanced Defence Research of the Bulgarian Ministry of Defence. In 1992, Prof. Ivanov was among the first Bulgarians graduating from the "Defense Resources Management Institute" in Monterey, California. He is an internationally recognised expert on economics and management of defence and security. Among his publications are the books Defence Economics (1997) and Defence Economics and Bulgaria's Security Policy in the mid-1990's (1999).

E-mail: tkivanov@unwe.acad.bg. 